\title{
HVMANITAS
}

\section{A partilha da dor e do silêncio: estratégias meta-teatrais no Prometeu Agrilhoado de Ésquilo}

Autor(es): $\quad$ Costa, Gilmário Guerreiro da

Publicado por: Imprensa da Universidade de Coimbra

URL

persistente:

URl:http://hdl.handle.net/10316.2/35068

DOI: $\quad$ DOI:http://dx.doi.org/10.14195/2183-1718_66_5

Accessed : $\quad$ 26-Apr-2023 09:46:56

A navegação consulta e descarregamento dos títulos inseridos nas Bibliotecas Digitais UC Digitalis, UC Pombalina e UC Impactum, pressupõem a aceitação plena e sem reservas dos Termos e Condições de Uso destas Bibliotecas Digitais, disponíveis em https://digitalis.uc.pt/pt-pt/termos.

Conforme exposto nos referidos Termos e Condições de Uso, o descarregamento de títulos de acesso restrito requer uma licença válida de autorização devendo o utilizador aceder ao(s) documento(s) a partir de um endereço de IP da instituição detentora da supramencionada licença.

Ao utilizador é apenas permitido o descarregamento para uso pessoal, pelo que o emprego do(s) título(s) descarregado(s) para outro fim, designadamente comercial, carece de autorização do respetivo autor ou editor da obra.

Na medida em que todas as obras da UC Digitalis se encontram protegidas pelo Código do Direito de Autor e Direitos Conexos e demais legislação aplicável, toda a cópia, parcial ou total, deste documento, nos casos em que é legalmente admitida, deverá conter ou fazer-se acompanhar por este aviso. 
humanitas

Vol. LXVI

2014

IMPRENSA DA UNIVERSIDADE DE COIMBRA

COIMBRA UNIVERSITY PRESS 


\title{
A PARTILHa da dOR E dO SILÊNCIO: eStratégias meta-teatrais no Prometeu AgrilhoAdo DE ÉSQUILO
}

\author{
SHARING THE PAIN AND SILENCE: \\ meta-theatral STRATegies in Aeschylus' Prometheus \\ BOUND
}

Gilmário Guerreiro da Costa

Universidade Católica de Brasília e Universidade de Brasília ${ }^{1}$ gilmario.filosofia@gmail.com

\section{Resumo}

Investiga-se neste ensaio um procedimento retórico recorrente no Prometeu acorrentado, de Ésquilo, o qual consiste no apelo ao público - e leitores - para verem o que veem as personagens. Exibe-se a cena da cena - a cena que se desdobra aos olhos das personagens, em jogo de visão que é a estratégia retórica e artística da peça para convidar os espectadores e leitores à filantropia, a se compadecerem do herói.

Palavras-chave: Ésquilo; cena; visão; estratégia retórica; filantropia.

\section{Abstract}

This paper investigates a recurring rhetorical procedure in Prometheus Bound, by Aeschylus, which is characterized by a appeal to the audience - and to the readers - to see what the characters see. It displays the scene of the scene - a scene that unfolds itself before the characters' eyes, a vision play, which is the rhetorical and artistic strategy of the play to invite audience and readers to philanthropy, to sympathize with the hero.

Keywords: Aeschylus; scene; vision; rhetorical strategy; philanthropy.

1 Bolsista de Pós-doutorado da CAPES-Brasil. 


\section{Introdução}

A identificação dos leitores com a peça Prometeu agrilhoado ${ }^{2}$ explica-se por diversos motivos, dos quais desponta o tema da resistência obstinada contra a tirania. Obtém-se semelhante efeito por intermédio de algumas estratégias retóricas de aproximação e distanciamento, notórias no apelo a que vejamos o que veem as personagens, como se deparássemos com a cena da cena - a primeira é a que se desenrola ante os nossos olhos, a segunda, aquela a que se referem as personagens, recurso revelador de composição meta-teatral. Daqui decorre uma intensificação das emoções e do processo da empatia, do ato de colocar-se em lugar de outrem, pois somos inseridos na perspectiva dos heróis e anti-heróis do drama, com focalização que, se por um lado se limita, por outro amplia a possibilidade de um saber pelo padecer, divisa peculiar ao autor da obra, Ésquilo ${ }^{3}$. As lágrimas das personagens, quando testemunham as diversas expressões de sofrimento na peça, espelham - e incentivam retoricamente - as lágrimas que se pode colher ao público ${ }^{4}$, assim oferecendo oportunidades de partilha da dor que se evidenciam nas palavras e nos gestos, e também no silêncio.

As duas cenas ligam-se por via metonímica. Os seus movimentos servem-se de um jogo da visão que é a estratégia retórica e artística da peça para convidar os espectadores e leitores à filantropia. A isso se soma a questão da temporalidade - o heroísmo de Prometeu configura-se no misto de coragem nas ações do passado e a rememoração resoluta dos seus

2 Todas as citações em português dessa obra procedem da tradução de Trajano Vieira (2007). Alterações pontuais, de minha autoria, foram devidamente identificadas. Com respeito ao título, optamos por Prometeu agrilhoado, algo mais preciso do que Prometeu prisioneiro.

3 Referimo-nos à máxima esquiliana do pathei mathos (A. Ag. 177), o aprendizado pelo sofrimento, expressão do corifeu acerca do modo como Zeus conduz os homens a um tipo de conhecimento dificilmente obtido por outras vias.

4 Efeito afim ao da catarse aristotélica: "A tragédia é a imitação de uma acção [praxeos] elevada [spoudaias] e completa [teleias], dotada de extensão [megethos], numa linguagem embelezada [hedysmenoi] por formas diferentes em cada uma das suas partes, que se serve da acção e não da narração e que, por meio da compaixão e do temor, provoca a purificação de tais paixões [pathematon katharsin]." (Arist. Po. 1449b 20-25 - trad. A. M. Valente). O teor da formulação aristotélica suscitou infindável polêmica. Era recorrente seja a defesa da acepção médica de "catarse", seja a direção ética. Na impossibilidade de analisar em pormenor os diversos ângulos do tema no espaço deste ensaio, apenas mencionamos que nos interessa sobremodo o perfil ético do efeito dramático da tragédia, embora não nos pareça incompatível com os elementos hipocráticos de que Aristotételes certamente se aproximou. 
A partilha da dor e do silêncio:

estratégias meta-teatrais no Prometeu Agrilhoado de Ésquilo

sofrimentos. Vemos encenar-se o espaço e tempo em perspectiva trágica. Tais elementos sublinham a profunda significação aos diversos temas que se entretecem na trama, e é o que nos propomos investigar neste ensaio.

\section{Aspectos da tirania de Zeus}

A autoria do Prometeu agrilhoado tem sido objeto de controvérsia ${ }^{5}$, com intensidade variada, desde o século XIX. Parte considerável da questão liga-se

5 Entre os que se recusam a atribuí-la a Ésquilo despontam Wilhelm Schmid, Mark Griffith e Martin West, os quais se serviram de argumentos provindos de análise estilística e métrica. Griffith levou a cabo trabalho rigoroso com o qual julgava apresentar dados bastantes para recusar-se a autoria esquiliana da peça. Apresentava o projeto de análise o mais objetiva possível da obra, de modo a colher respostas satisfatórios a essa questão, em busca de comparar-se em bases mais factuais o Prometeu com as demais obras supérstites de Ésquilo: "This can only be done if we can discover and apply truly objetive criteria to the available material" (GRIFFITH, 1977, p. 3). Em que pese a notória seriedade na condução de um trabalho elogiável do ponto de vista metodológico e da erudição, componentes artisticamente cruciais à peça colocaram-se à margem por não se adequarem aos requisitos de objetividade anunciados. Tal escolha conduziu a resultados discutíveis.

Diferentemente, parece a outros estudiosos, tais como S. Saïd, J. Herington e A. P. Sottomayor, serem insatisfatórias as razões apresentadas contra a autenticidade da obra. Ao término de uma apreciação minuciosa do trabalho de Griffith, Saïd afirma que as razões para seguir-se a tradição ainda são preponderantes: "Car cette tradition est tout à la fois unanime et ancienne. Elle remonte au moins à Aristophane de Byzance et, au-delà, aux didascalies d'Aristote qui reposaient sans doute sur des documents officiels athéniens." (SAÏD, 1985, p. 80). Herington, por seu turno, manifesta dúvidas sobre a capacidade de um método científico medir os diversos níveis estilísticos de um grande poeta: "by what scientific method can one define the sylistic or metrical capacity of a poet of this stature?" (1986, p. 183). Além disso, os principais temas das peças supérstites do escritor grego encontram-se no Prometeu agrilhoado. Finalmente, Sottomayor acrescenta ainda duas ponderações que servem de justo reparo à tese de Griffith. Lembra que nos chegou apenas um décimo das peças do poeta grego, quantidade insuficiente para se elaborar análise estilística abrangente da sua obra. Chega a mencionar o aparecimento de novos fragmentos da peça Níobe, com traços estilísticos afins ao Prometeu: "formalmente apresentam traços estilísticos divergentes da maioria das obras conservadas de Ésquilo, mas que, como notou Max Pohlenz (Die griechische Tragödie, p. 84), se aproximam dos do Prometeu Agrilhoado." (SOTTOMAYOR, 2008, p. 19). Aos três é comum a referência ao fato de jamais ter sido posta em dúvida na Antiguidade a autoria esquiliana da peça.

Vale ainda mencionar a posição do R. P. Winnington-Ingram, elogiável em sua honestidade - pois confessa a dificuldade em tomar posição. Sugere que possivelmente se assumiu com excessiva presteza a existência de apenas três grandes tragediógrafos, graças ao testemunho de Aristófanes e Aristóteles. (WINNINGTON-INGRAM, 2008). Revela-se 
à peculiaridade do caráter de Zeus na peça, que difere substancialmente de sua imagem em outros textos de Ésquilo por força do exercício implacável do seu poder que a obra não cansará de sublinhar, sobretudo no castigo inclemente imposto a Prometeu. A repetição do termo "tirano", aplicada ao soberano dos deuses, se lhe atribuía uma imagem desfavorável junto ao público, o que não se observava nas outras composições do escritor grego. É de fato uma das questões difíceis do drama, que motivou respostas as mais diversas. Grande parte delas buscou harmonizar as diferenças com a hipótese de que Zeus haveria de ser reabilitado na peça seguinte da trilogia (PODLECKI, 1999; SOTTOMAYOR, 2008). Seria plausível esperar mudanças na caracterização das personagens - embora, como destacaremos adiante, se deva precaver contra os riscos de um esquema evolucionista imposto a esse problema.

Modo mais satisfatória se ligaria ao confronto entre o poder novo, representado por Zeus, e o antigo, cuja reconciliação se faz mediante a persuasão, sob pena de deitar a perder numa infinda espiral de violência a história futura. É um texto, nesse sentido, que lida recorrentemente com pensar os limites da violência ${ }^{6}$, e "démontre avec éclat la puissance d'une juste persuasion et affirme avec force que seul un ordre qui se fonde sur le respect et sait dépasser l'opposition de l'ancien et du nouveau est à l'abri de la destruction." (SAÏD, 1985, p. 20). Deste modo, o retrato de Zeus não chega a contradizer aquele encontrado na Oresteia, por exemplo. Notar-se-ia tão somente uma diferença de ênfase, sobre uma base comum, a de que o poder que se exerce baseado exclusivamente no medo é assaz frágil e pouco dura, enquanto aquele que se fortalece por meio de um misto de temor e respeito (sebas) destina-se com mais probabilidade a ser estável.

Embora sejam plausíveis todos esses reparos com respeito ao delineamento da figura de Zeus na peça, não diminuem o impacto dessa caracterização cênica sobre o público. Não deixa de representar considerável

um exercício de cautela sobremodo curioso, pois não deixa de disseminar considerável desconfiança sobre temas já carregados de polêmica.

Embora se trate de questão difícil e ainda distante de repousar em alguma sorte de consenso entre os especialistas, inclinamo-nos em favor da autenticidade da peça. Os argumentos em favor da autoria esquiliana ainda se nos afiguram os mais consistentes.

6 Suzanne Saïd estuda em pormenor essa questão (SAÏD, 1985, p. 292-310) e apresenta resultados bastante convincentes. Parece-lhe reforçar-se ao longo da peça os efeitos paradoxais do poder exercido por Zeus. Quanto mais exibe a sua força, mais vê enfraquecer-se a obediência de quem é objeto da sua tirania. Assim, o Prometeu agrilhoado "met en lumière 1'impuissance relative de la force." (Idem, p. 282). 
ironia o fato de ter sido precisamente essa parte da trilogia a que foi conservada ao longo da história - a imagem tirânica do deus dos deuses. É improvável que ninguém se sentisse intensamente atingido por esse quadro, ainda que nas peças subsequentes o escritor lograsse êxito em oferecer uma harmonização satisfatória - supondo-se que se tratasse efetivamente de uma trilogia. Contra essa figura se levanta o protagonista, Prometeu. A assimetria de forças e a tensão disso resultante estrutura parte considerável da peça.

\section{O sofrimento e os silêncios de Prometeu}

O silêncio em uma peça teatral necessita ser devidamente qualificado. Não raro, dá-se tão somente por limites cênicos, sem que nele se insinue qualquer outra razão mais significativa. Há, no entanto, situações em que o silêncio é deliberado - obedece a uma intenção semântica da obra. Convida o público a refletir a seu respeito, e está repleno de significado - não é mera ausência, mas uma falta que se pretende significativa precisamente por sua ausência. Por essa razão, Oliver Taplin julga crucial identificar-se a diferença entre os dois tipos de silêncio, operação capaz de conduzir o trabalho de interpretação das peças a um nível mais consistente e fecundo: "This basic distinction between silences which are and are not significant, which do and do not have attention drawn to them, is vital." (TAPLIN, 1972, p. 57). Diferentemente do teatro moderno, pontuado de silêncios, no drama antigo o uso de semelhante expediente era escasso - havia a tendência à continuação de som. Trata-se de comentário sobremodo importante, pois nos franqueia instrumentos capazes de oferecer mais precisão à análise do significado do silêncio nas peças trágicas: "In surviving Attic tragedy there is scarcely anywhere, so far as I can see, where the text obliges us to suppose a total silence of more than a few seconds." (TAPLIN, 1972, p. 57). "Trata-se de comentário sobremodo importante, pois nos franqueia instrumentos capazes de oferecer mais precisão à análise do silêncio nas peças trágicas”.

Taplin procede a cuidadosa análise dos fragmentos das peças Mirmidões e Níobe, com vistas a atestar o alcance de uma hipótese que elabora em diálogo com Aristófanes, em As rãs (905)7. Permite-lhe estabelecer uma distinção bastante útil entre um "silêncio esquiliano", como resultado de

7 Na peça, Eurípides observa: "Logo de entrada, ele [Ésquilo] fazia sentar uma figura qualquer velada, um Aquiles ou uma Níobe, ocultando-lhe o rosto, figuras da tragédia que não tugiam nem mugiam.” (Ar. Ra. 911-913). Um pouco adiante Dioniso contrapõe-se 
uma estratégia de reflexão, e não apenas um "silêncio em Ésquilo", ligado a necessidades técnicas e cênicas. Após esse itinerário, passa a ocupar-se da questão no conjunto das obras supérstites do escritor grego. Na grande maioria delas encontra elementos característicos dos limites técnicos do teatro, particularmente do grego, caso em que a busca por alguma sorte de significado mais profundo nesse recurso conduz a evidente frustração. Os únicos momentos em que o silêncio das personagens timbram em tonalidade significativa ligam-se a Cassandra, no Agamemnon, e Prometeu, na peça homônima: "silences which are the object of direct attention, so that the questions arise why the person is silent, and how and when he will break his silence." (TAPLIN, 1972, p. 94). A ênfase recai na expressão "atenção direta", exigência que se revela especialmente necessária no teatro antigo. O silêncio de Prometeu deve-se à sua insubmissão titânica. A exemplo do de Aquiles e Níobe - nos fragmentos de Mirmidões e Níobe, respectivamente -, é o único que se desdobra logo no início da peça. No entanto, o uso que o escritor grego faz desse expediente teria sido bastante modesto: "Yet Aeschylus does not make much use of this silence." (TAPLIN, 1972, p. 78). Esta conclusão, no entanto, se nos afigura insatisfatória, por ser precisamente a articulação entre silêncio e tirania um dos eixos estruturantes da peça. Em que pese esse reparo, a distinção entre os dois tipos de silêncio evidenciada por Taplin lança luz considerável no estudo do Prometeu agrilhoado, e nos permite esclarecer tratar-se de um "silêncio esquiliano" aquele acerca do qual nos ocupamos neste ensaio, cuja significação profunda advém de uma resposta à tirania de Zeus.

É significativo a esse respeito o fato de não apenas Prometeu, mas todas as personagens da peça, mesmo que divinas, refletirem algum nível de relacionamento com o poder autocrático do soberano dos deuses: a obediência relutante de Hefesto; o sadismo de Poder; o lamento das Oceânides; o conselho pragmático de Oceano; Io, vítima inocente da tirania; a cumplicidade cínica de Hermes. Todos encontram-se inextricavelmente ligados à tirania - do sofrimento ao lamento, até a aceitação interesseira (HALL, 2010, p. 229). Uma breve análise dos diálogos que se entretecem na peça pode demonstrá-lo.

Prometeu vê-se punido por ousar roubar o fogo a Zeus, e entregá-lo aos homens. A cena inicial da peça revela os preparativos do castigo, sob os cuidados dos emissários de Zeus, o Poder (Kratos) e a Violência (Bia).

a essa censura: "Eu gostava desse silêncio [tei siopei] e isso me dava um prazer não menor do que os tagarelas de agora." (916 - tradução de Américo da Costa Ramalho). 
Obrigam Hefesto a cumprir o plano, que se resume a prender o cativo com correntes a uma rocha. A isso Prometeu observa em silêncio. Quando os três saem, e o deixam sozinho, ouvimos as suas primeiras palavras, expressas em dor e solidão. Ao longo da obra receberá algumas visitas - as delicadas Oceânides, o prudente Oceano, a desventurada e delirante Io, sua companheira de martírio. Todos reagem ao sofrimento físico do titã, ora comentando-o, ora partilhando a sua dor e instigando-o a passar do silêncio ao logos. Também aparece o cínico e soberbo Hermes, o qual insta com o herói para que se vergue às ordens de Zeus, e revele um segredo que ameaça o futuro do reinado do soberano dos deuses, mas em vão. A recusa lhe custará novo sofrimento, o de ser encerrado em abismo profundo, aonde irá carpir sua dor pelos séculos por vir.

Em sua primeira intervenção, na abertura do drama, Poder refere-se ao espaço em que se encontra, na terra cítia: "deserto inacessível (abroton eis eremian ${ }^{8}$ )" (A. Pr. 2). O adjectivo abroton auxilia na conformação de um quadro semântico tão rico quanto preciso, fazendo sobressair o território de uma ausência de pessoas queridas. Mark Griffith, em seus comentários ao texto de Ésquilo, observa com precisão: "far from those whom P. has loved and helped" (GRIFFITH, 1983, p. 81). A personagem Poder esclarece sua função de "aprisionar o criminoso" (A. Pr. 143), já traindo, no adjetivo empregado, disposição inexorável.

Ao longo da peça se vai delineando em Prometeu a figura de nosso sonho de superação da indiferença, mesmo que lhe custe temível sacrifício so recusar a posição de mero espectador passível das desventuras dos homens. A isso faz menção Poder, quando se reporta ao ultraje (9: hamartias) cometido por Prometeu, movido que estava por gestos filantrópicos (11: philanthropou ... tropou). Para o emissário do tirano, um sacrifício que diminuía com justiça o supliciado; para as demais personagens (e o público), a razão de crescer na admiração de todos.

Hefesto cumpre com dissabor a sua missão. Enaltece as altas qualidades de Prometeu (8), em especial os seus pensamentos elevados (18: aipymeta). Sublinha a solidão do herói, assim ampliando, com arte notável, as frases iniciais de Poder (19-21). Encontra-se numa rocha em lugar desértico (apanthopoi pagoi). Não lhe chegam nem voz nem forma humana (21: oute phonen oute tou morphen broton). Destaca-se nessa cena o elemento visual, por sinal impressivo durante toda a peça, e que garante a espetacularidade

8 Utilizamos a edição grega preparada por Mark Griffith (AESCHYLUS (1983). 
cênica tão cara ao teatro esquiliano em geral - Prometeu é acorrentado em uma rocha sob o olhar do público e assim se mantém ao longo da peça. Constroi-se assim o quadro de uma reclusão radical. Fere entrementes uma nota recorrente na peça - o caráter arrogante do novo soberano, afim ao novo exercício do poder: "é duro quem exerce poder novo" (35). O novo por vezes se revela ambíguo: é de certo modo portador de esperança, mas também de temor, pois ainda não lhe moldou o tempo, que a tudo atenua e esquece.

No diálogo com Hefesto - Violência está presente, mas é uma personagem muda ${ }^{9}$, Poder avisa que nada adiantará lamenter o destino de Prometeu: "Não há remédio no lamento." (43) O temperamento de Poder é o emblema da compaixão impossível. No conflito de definições do agon com Hefesto, o que este julga necessário sentir, para aquele é tão somente fraqueza: "Frouxo" (79). Contrapõe-se a esse suposto acovardamento a amostra da sua obstinação e rigidez (authadeia). Afirma ainda que o único ser a conhecer a liberdade é Zeus (50). No plano interno, essa afirmativa refere-se a um atributo que seria apanágio do soberano dos deuses. No plano mais amplo, a focalização encerra a mensagem de que em um regime de opressão, ninguém seria livre, salvo o tirano. Griffith, no entanto, faz um lembrete importante: "Later we shall see that even Zeus' freedom is severely limited (517-18, 926-7)." (GRIFFITH, 1983, p. 93).

O pesar de Hefesto, tantas vezes manifesto, é ambíguo - pelo condenado, mas também por si mesmo, pois lhe coube o papel de carrasco: "Como odeio a perícia dos meus dedos!" (A. Pr. 45). Neste verso depara-se-nos o microcosmo de uma ambiguidade que se estende a toda a peça - toca a ambivalência dos progressos da civilização. É uma passagem notável: Hefesto, o deus artesão, muito odeia (o polla misetheisa) as habilidades manuais (cheironaxia) que são seu traço distintivo e admirado por deuses e

9 Anthony Podleci, em passagem sugestiva, divisa a presença de Bia, Violência, ao longo de toda a peça: "Bia, Violence, though a mute character (adressed by Hephaestus at line 12), makes her presence felt not only in the opening scene, but through almost every line of the play." (PODLECKI, 1999, p. 107). Walter Benjamin já observara que a instauração do direito não se faz sem o exercício da violência, que se tentará ocultar adiante mediante o apagamento dos seus traços genealógicas em narrativas futuras com função ideológica legitimadora. Sublinhe-se sua interpretação do direito enquanto violência mítica metamorfoseada - o traço demoníaco do direito (BENJAMIN, 2011, p. 134s), um veio interpretativo possivelmente fecundo para se indagar a natureza da instauração do novo poder de Zeus e do direito a ele associado - ou mesmo, da peculiaridade do direito em situações de tirania. 
homens. Lamenta o sofrimento de Prometeu, em frase que paradoxalmente se intensifica pelo silêncio do titã - que apenas tomará a palavra no verso 88: "Ai, Prometeu, deploro a tua pena." (66).

Quando saem Poder, Violência e Hefesto, vê-se Prometeu sozinho. Em seu monólogo, menciona ser a causa da sua vergonhosa prisão (97) o castigo ordenado pelo novo comandante dos deuses (96). Lamenta o sofrimento (99: pema) que lhe sobreveio e, um tanto enigmaticamente (106-7), afirma que não pode nem silenciar, nem falar sobre as suas adversidades, pois ambas as ações se equivalem. Qual a razão dessa assertiva? Insinuaria a inutilidade de ouvi-lo, dada a situação em se encontra, ou ainda pela indiferença de muitos? Adiante (196-7) retoma ideia semelhante, agora acrescentando que lhe causa sofrimento seja o falar, seja o guardar silêncio. O titã insiste em dizer que paga hoje pelos benefícios dedicados aos homens (107-113), recebendo, em vez de reconhecimento, o martírio sob as ordens de Zeus. Declara ainda a filantropia que o move, um dos motes da peça: "Me liga aos homens [broton] forte liame" (123). O termo brotos aduz a finitude e fragilidade ${ }^{10}$ humana, ressaltando sobremaneira o generoso dom ofertado pelo herói, vazado em afeição e amizade. Há no texto uma partícula que intensifica esse amor: lian, "em demasia", "profundamente". Esse traço é essencial à identificação do público com o protagonista, o qual timbra em ser não apenas um intransigente adversário da tirania, mas também um fervoroso amigo da humanidade.

A certa altura menciona ouvir um barulho, mas ainda não sabe de que se trata: "Ai" Estranho rumor! Aroma sem figura me circunda" (115). Em um crescendo admirável, o prisioneiro pode finalmente discernir a natureza dos sons a que se referia: trata-se de asas que se aproximam, e o deixam irrequieto (127), até finalmente se revelarem as Oceânides, as delicadas filhas de Oceano. Elas dizem imediatamente a Prometeu (128-129) que nada tema, pois são suas amigas. Ainda pesava na memória de muitos o som duro e ritmado dos pregos e grilhões com que o amarrara Hefesto. O contraste não poderia ser mais oportuno. Também a acolhida gentil dessas personagens opõe-se ao tom implacável de Poder. O público logo testemunhará semelhante antítese, e estará em boas condições de decidir-se - ao menos cenicamente - pelos polos em disputa.

As Oceânides confessam a sua surpresa com a ousadia e intrepidez (thrasys) do titã (178), cujo ânimo incoercível, mesmo na fraqueza, equivale ao teor inquebrantável de Zeus. Prometeu relata que após Cronos ter sido

10 Conferir a esse respeito Loraux (1992). 
destronado, buscou aconselhar os titãs para que agissem de modo atilado e com engenho, mas sem sucesso - a este alvitre preferiram o caminho que lhes parecia mais fácil, o da violência (208), uma escolha que os poria inelutavelmente a perder. A mãe do protagonista, Têmis, já lhe havia dito (213) que o vencedor seria quem se servisse de astúcia (dolos), e não da força pura e simples. Com essa resposta, Prometeu viu-se premido a auxiliar Zeus. No entanto, mesmo tais ressalvas não deixam de esbater a imagem de um herói de alta estirpe, intrépido e infenso a barganhas. É uma fissura nada desprezível em seu passado. No mínimo, convida à prudência com respeito ao modo idealista com que rapidamente cobrimos nossa interpretação da personagem.

Prosseguindo em seu relato, ele conta ainda que Zeus, uma vez vitorioso, planejou destruir todos os homens, criando nova raça. Prometeu interveio a tempo de impedir que esse intento de concretizasse, e ainda haveria de presentear aos mortais ao preveni-los de tomar conhecimento do seu destino (moros), do dia da sua morte (250), a insuflar-lhes falsas esperanças (typhlas ... elpidas). Mas ele que uma vez demonstrou piedade (oiktos) pelos homens, não recebe em paga senão um tratamento impiedoso (neles).

Chega em seguida o próximo visitante, Oceano, que afirma ser solidário com os sofrimentos do titã (288), dele compadecendo-se (synalgo). Faz uma referência ao oráculo de Delfos (309: "gignoske sauton"), sem

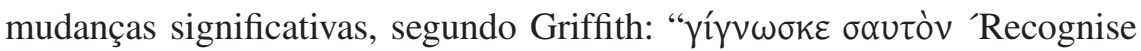
who (or what) you are' (...) inscribed over the entrance to Apollo's sanctuary at Delphi, and regularly quoted to admonish the proud or ambitious to recognize their limitations." (GRIFFITH, 1983, p. 144). Não obstante, a referência logo a seguir ao novo tirano (A. Pr. 310) insinua um conselho mais afim à conveniência que à virtude. Em uma tirania, o "conhecer-se a si mesmo", apanágio de um espírito livre, torna-se em busca dos meios de melhor adaptar-se - a linguagem mesma contamina-se.

Prometeu prodigalizou aos homens os saberes necessários à feitura e progresso da civilização (450-506): casas e trabalho com madeira. Ensinou-os a observar os astros e discernir as estações, a conhecer os números e escrita, a domesticação de animais, a navegação, a medicina e a mineração. Ele assim o resume: todas as artes humanas devem-se a Prometeu (506). Aqui se evidenciam diferenças importantes com respeito ao relato de Hesíodo (Hes. Th. 507-616), com a predominância dos benefícios do progresso técnico, e não da decadência da Idade de Ouro. É necessário, no entanto, tomar-se em consideração as ressalvas de Saïd (1985), as quais esbatem esse otimismo, e que teremos oportunidade de examinar com mais vagar 
adiante. Note-se como, alguns versos adiante, as Oceânides, após tecerem o desejo de que tenham vida longa e feliz, manifestam seu desconforto com Prometeu: ele se lhes afigura a efígie da fragilidade da existência. Afirmam estremecer (phrisso) ante a exposição do sofrimento de um deus acorrentado (A. Pr. 540).

A entrada em cena de Io é intensa e dolorosamente visual. Vem com chifres, assemelhada a uma rês, resultado de um castigo injusto infligido por Zeus, além de ver-se atormentada pela picada de um moscardo (oistros) - se imaginário ou real, não é fácil discernir. Da mesma palavra já se haviam utilizado outros escritores para referirem-se a algum tipo de delírio humano. Mas é incerto se o seu uso na peça é literal ou metafórico (GRIFFITH, 1983, p. 195). Desdobra-se uma impressionante cena de encontro dos desafortunados (A. Pr. 594-5), de dois seres em temível estado de sofrimento, vítimas da tirania. Também inquieta o contraste entre as posições de ambos - Prometeu em correntes, Io a correr (p. ex., 622), sem que disso se possa divisar qualquer saída, ao invés, apenas reforçam a fragilidade do estado de cada uma das personagens: a imobilidade do titã ganha relevo com os movimentos de Io, ao mesmo tempo em que sublinha o desvario dos gestos frenéticos da sua visitante. Todos esses recursos permitem que a cena contrastante das duas vítimas de Zeus movimente as emoções dos espectadores a nível crescente de intensidade. A saída de Io (885-6), por fim, é acompanhada por expressões de profunda dor e delírio, cujo impacto quadra-se à perfeição com a sua entrada em cena (561) e os diálogos que entreteve com Prometeu, seu companheiro de dores e sevícias.

As Oceânides enunciam em oximoro imagem que marca a irredutibilidade do sofrimento de Prometeu e Io à linguagem. Estes dois testemunham uma luta que não se pode lutar (904): "apolemos ... polemos". Trajano Vieira propôs uma bela tradução para a frase: "A luta é luto". Não configura um simples reforço estilístico, em razão de serem os impasses mesmos do enredo e o caráter em última instância inexprimível do sofrimento o que se pode intuir na luta da frase com o silêncio, estratégia coerente com os riscos em que se detêm as personagens na resistência a um poder arbitrário.

Em todas as intervenções das personagens ressoa uma nota comum: a afirmação da vontade inquebrantável de Zeus, do novo poder que se exerce por via extremada e infenso ao menor gesto de compaixão. Em mais de um momento, sustentam ser inútil a resistência ao novo regime. Mas se do ponto de vista político o confronto favorece o tirano, cenicamente é o prisioneiro quem sai vitorioso, o único herói verdadeiro da peça, a erguer-se paradoxalmente triunfante em sua queda. 


\section{O lamento e a meditação sobre os efeitos da tirania}

Prometeu agrilhoado foi terreno fértil para a busca de sujeitos históricos a que a figura de Zeus supostamente se referiria. Sobram motivos para desconfiar-se desse tipo de investigação. Podlecki apresenta alguns deles quando nota que ao insistir no mero retrato alegórico de um tirano, o estudioso arrisca-se a esquecer o traço ficcional que alimenta toda arte genuína. Não temos dificuldade em subscrever semelhante advertência, coerente com o pressuposto de que uma obra de arte é algo mais do que um documento de época: "It is one thing to say that Aeschylus drew on real tyrants whom he knew or had heard about for realistic details of portraiture in his treatment of Zeus; quite another to believe that he was writing poetic allegory." (PODLECKI, 1999, p. 111). Da utilização de traços peculiares aos tiranos historicamente existentes não se segue a representação servil de uma determinada figura histórica.

Feitas essas ressalvas, Podlecki sugere haver no Prometeu agrilhoado, ainda que indiretamente, considerável presença da luta de Temístocles contra a tirania, líder político que Ésquilo aprendera a admirar havia muito: "In molding his ultra-tyrannical Zeus at the end of his career, may not Aeschylus have been reflecting - if only incidentally - influences to which he had been exposed decades before by the politician he so much admired?" (PODLECKI, 1999, p. 117). A luta dos atenienses contra a tirania se foi reforçando por todos os lados, o que em grande medida explica o fascínio exercido pelo alvorecer da experiência democrática. Tal reação viria a manter-se forte no século seguinte, mesmo entre autores infensos à democracia, como Platão e Aristóteles. Segundo o autor, a Política de Aristóteles contém um arrazoado crítico da tirania muito próximo do que encontramos no Prometeu. O capítulo nove no livro V da Política trata dos meios pelos quais se mantém uma tirania. $\mathrm{O}$ foco reside na luta contra todas as personalidades excepcionais e orgulhosas, e contra grupos de discussão que poderiam fortalecer o ânimo de seus membros na luta contra o regime opressor. Oceano parece mesmo sugerir que Prometeu é castigado por suas qualidades excepcionais: "Ocean had suggested snidely that Prometheus was too wise for his own good, perissophrôn (328), and he is urged by Hermes to mend his thoughts, orthôs phronein (999)." (PODLECKI, 1999, p. 119). Ésquilo antecipou-se dessarte a um tratamento da tirania que haveria de tornar-se modelar. 
Podlecki retira ainda à peça um outro elemento político de relevo. Refere-se ao verso 324, quando Oceano assevera ser Zeus um monarca incompassivo que não presta contas da sua administração a ninguém. Não passaria despercebido ao público a menção implícita ao instituto democrático da euthynai, que exigia, de quem exercia cargo na magistratura, a prestação de contas ao término do seu mandato (PODLECKI, 1999, p. 115).

Tais esforços analíticos, posto que modelares, ainda resultam insuficientes para conceder uma interpretação convincente a uma passagem que insiste em desafiar-nos. Quando Prometeu questiona a violência (A. Pr. 735) enquanto marca das ações de Zeus, lança uma nuvem de dúvidas sobre o público. É pouco provável que não tenham, ao menos alguns deles, chegado a especulações semelhantes às de Xenófanes ${ }^{11}$, acerca da representação justa da divindade, embora com resultados diversos. É duvidoso que mesmo em se tratando de festa cívica, a tragédia não tenha resultado em inquietações individuais. $\mathrm{O}$ modo como Platão ${ }^{12}$ a isso reage, buscando imagem que se lhe afigurava mais coerente da natureza dos deuses, parece demonstrá-lo. Além disso, a peculiaridade da reflexão acerca do sofrimento na tragédia desestabiliza a posição cômoda perante a simples reprodução de valores cívicos. Nicole Loraux intuiu o núcleo desse problema quando sublinhou a função do lamento na tragédia grega, o qual esmaece sua tonalidade política: "expressions of mourning have become, if not a weapon of war, at least the only weapon in a struggle that is unarmed, or hopeless." (LORAUX, 2002, p. 13). As suspeitas que assim enunciamos esteiam-se no princípio de que o texto literário, por sua multiplicidade de planos, e por não limitar-se a ser mero documento de época, suscita reflexões que não se subsumiriam ao quadro institucional e social vigente.

Autor de ações de inexcedível heroicidade no passado, Prometeu surge em cena como a imagem da reflexão, ainda que exercida predominantemente em tom de lamento. O contraste implícito que assim se constrói prepara retoricamente a identificação entre o público e o protagonista - por via semelhante ao que se observara com a empatia expressa pelas Oceânides. Faz-se uma exposição meditativa das ações que tiveram lugar em tempo e espaço diferentes da peça, com ênfase a recair sobre o que adveio ao herói, em uma espécie de denúncia contra os seus algozes no presente. Daí que a "segunda cena", acentuadamente meta-teatral, revele toda a sua força e

11 Conferir, por exemplo, Xenoph. DK B 11, 12 e 15.

12 Tome-se esta passagem do livro III da República: "é impossível que o mal venha dos deuses" (Pl. R. 391e - trad. Maria H. Rocha Pereira). 
importância artística, pois visa à exibição às outras personagens e ao público dos meandros e efeitos da tirania sobre o conjunto da vida.

\section{Estratégias meta-teatrais e vocabulário visual}

Seja o público, sejam os leitores, testemunham o castigo que sobrevem a Prometeu, sob todos os aspectos excessivo. Mas não apenas isso. Em diversas passagens, são convidados a experimentar o ponto de vista das personagens de modo a observarem o que elas veem, arrebatadas de seu lugar de conforto para situarem-se junto à cena, sujeitas a um incessante trabalho de aproximação e distanciamento. Movimenta-se um jogo que extrai da identificação catártica seu segredo mais importante. A este sofisticado artifício de linguagem chamamos de segunda cena. Em face desse quadro complexo o público testemunha um drama que se orienta por um processo de sedução trágica de aproximação da distância, ou ainda, um lembrete de que a identificação catártica nunca pode abolir por completo a distância entre o público e as personagens, e nessa fissura criam-se as condições para a resistência à indiferença. A impressão majestosa da obra esquiliana vem mesmo fortalecer essa hipótese, se sublinharmos o caráter da representação - a majestade que se faz tendo como fio condutor o sofrimento do herói trágico.

O plano cênico inicial da inserção de Prometeu é a esse respeito revelador, ao evidenciar uma dupla ausência: inicialmente, por via do silêncio; em seguida, pela falta de movimento e capacidade de ação. A palavra torna-se na única arma que lhe resta: "Porque imóvel e incapaz de reagir pela acção, toda a força de Prometeu se concentra na arma que lhe resta, a palavra." (SILVA, 2005, p. 54). O silêncio também se quadra com a nobreza de caráter de Prometeu, sobretudo por seu comportamento inflexível quando seus algozes tentam vergá-lo ao alvedrio de Zeus. A cena duplicada em traços meta-teatrais é marcada pela ausência e fragilidade, a oposição entre a carência de Prometeu e o excesso de Zeus. Aonde se situaria a moderação, é matéria de conjectura. Em todo o caso, parece deixar-se aos dois públicos que assistem ao suplício - os demais personagens e a plateia (ou os leitores) - as sugestões de composição de sínteses legítimas, embora provisórias. Assim, em cenas em que abundam os signos do poder absoluto, a peça constrói-se para tornar em herói o elo frágil em toda essa cadeia. Esteticamente, é o triunfo da 
fragilidade sobre a tirania. Também se pressente a inversão no fato de o sem-poder, Prometeu, ser o portador de um segredo capaz de destituir o todo-poderoso Zeus. É na sutileza do saber que se insinua a vitória sobre a prepotência da tirania.

A peça notabiliza-se pelo jogo de presença e ausência. Presença de Prometeu, o herói altivo e sofredor, e ausência de Zeus, o tirano; diálogos com palavras de acentuada intensidade dramática, marcados por contrastes e tensões, e o silêncio de Prometeu em metade dos versos. Surpreende assim não apenas a escassez de ação propriamente dita, mas também espécie de ato de resistência à palavra. Allan Sommerstein sustenta haver na peça uma mudança no significado do silêncio de Prometeu. No início, aduzia à sua impotência; no final, encerra o segredo precisamente do seu poder. Nisso residiria o cerne dramático dessa obra (SOMMERSTEIN, 2010, p. 221). Constitui-se numa peça sobre o silêncio que ora sofre, ora resiste à tirania - contrapõe-se outrossim ao palavrório que acompanha a tirania, com os seus atos de exceção, sob a dura égide de uma indiferença planejada. Mediante o uso significativo dos seus silêncios e ausências a peça joga coerentemente contra a presunção de onipresença e fungibilidade semântica afins a todo gesto autocrático. Trata-se, para nos servirmos da distinção de Taplin (1972), de um "silêncio esquiliano" por excelência, e não apenas de um "silêncio em Ésquilo". O impacto cênico desse silêncio também se pode medir por meio de alguns números: Prometeu apenas começa a falar a partir do verso 88. O total de versos da peça é de 1093, sendo 546 aqueles em que Prometeu intervém, ou seja, apenas metade (SOMMERSTEIN, 2010, p. 232, nota 5).

Em um trabalho dedicado à questão do espaço na tragédia grega, Rush Rehm formula a certa altura um conceito que nos interessa diretamente aqui: o de "espaço eremético", mediante o qual se esclarecem as exigências cênicas da Antígona, Ájax, Filoctetes e Prometeu agrilhoado (REHM, 2002). O termo "eremético" liga-se à palavra grega eremia, que significa "deserto", "solidão", "vazio" (LIDDELL e SCOTT, 1940). Rehm sublinha que o termo toma parte do nosso vocabulário por sua vinculação às práticas monásticas cristãs. Assume, assim, o sentido positivo de afastamento das tentações de um mundo ímpio. Entre os gregos antigos, ao invés, assume a acepção negativa de ausência, sobretudo em termos políticos: "For the Greeks of the fifth century B.C., however, no such positive valence existed for hermetic isolation." (REHM, 2002, p. 114). Mas esse estudo não se restringe apenas a descrever o caráter desértico 
do espaço em que se move inicialmente a peça, mas também a solidão de Prometeu. Os termos referidos a espaço bem o explicitam: v. 2: eremia: deserto; v. 2: abatos: não percorrido, não trilhado; v. 20: apanthropos: distante dos seres humanos; v. 270: eremos: desértico; ageitonos: sem vizinhos; v. 416-7: gas eschatos topos: lugar mais distante da terra (REHM, 2002, p. 156).

Tal análise permite melhor compreender o sentido de alguns jogos de ambivalência na peça. Move os fios da sua crítica política a partir de espaço notadamente não político, porque externo à pólis. Os limites entre ambos tornam-se problemáticos, subvertendo a nitidez dos discursos de legitimação da pólis, numa tour-de-force que marca um dos elementos mais fecundos da contribuição de Ésquilo ao pensamento político. É nesse contexto que Rehm aproxima-se do jogo de olhares que sustenta a hipótese do nosso trabalho. Mas focaliza a questão em Prometeu, e não no público: "He is the other characters' audience and ours, just as we are his, a process of mutual observation that runs through the play." (REHM, 2002, p. 163). A ideia da "mútua observação" é sugestiva. Parece-nos, no entanto, ser possível demonstrar que a sua grande força evocativa ainda reside na duplicação da cena de modo a "intimar" o público a uma posição de testemunha. Relativamente à denúncia da tirania, porém, ambas as nossas hipóteses se robustecem pelo lugar do olhar e da audição no jogo de "sequestro de consciência" que movimenta a violência em regimes de exceção.

No decurso de um estudo que ilumina ângulos importantes da peça, Edith Hall sustenta ser a peça provavelmente a que investe com mais intensidade na exposição do sofrimento das personagens. Prometeu e Io são postos frente às outras personagens e ao público enquanto modelos de identificação - de um sofrimento cujo núcleo pode-se intuir, sem que desse conhecimento se tenha encontrado a mínima possibilidade de preveni-lo: "Prometheus is the prototype in one sense not only of every tragic sufferer, but in another of every spectator: he is all-knowing, conscious of the meaning of his torment, and yet totally unable to prevent it." (HALL, 2010, p. 230). O conhecer na tragédia parece tardio e inútil. Conforme a boa fórmula da autora, é divino o conhecimento de Prometeu, mas é humana sua vulnerabilidade física: "His understanding is divine; his physical vulnerability to confinement and torture make him seem all too human." (HALL, 2010, p. 230). Conhece como os deuses, mas sofre como os homens. Poucas peças avizinham-se com tamanha intensidade da essência do trágico, de sua revelação íntima. 
Nessa peça, por conseguinte, afim à substância do pensamento, é a necessidade cênica. $\mathrm{O}$ caráter estático do protagonista exige apuradas soluções dramáticas, e no caso em apreço, o recurso à identificação das outras personagens e do público por meio da visão e da escuta provê os instrumentos necessários à condução a perfeito arremate artístico do conjunto da obra. Tome-se, por exemplo, um verso bastante musical e melódico, em que Hefesto tece este diálogo com Poder, quando lamenta o infortúnio de Prometeu: "A cena que tu vês corrói a vista." (A. Pr. 69) A palavra para cena é theama, que pode também ser vertida por "espetáculo". A repetição da partícula the em theama dystheaton amplifica a força da cena que se dobra sobre o público, de um espetáculo (theama) sob todos os aspectos doloroso, difícil de ver (dystheaton). Griffith esclarece tratar-se de um oximoro [ $\theta \dot{\varepsilon} \alpha \mu \alpha$

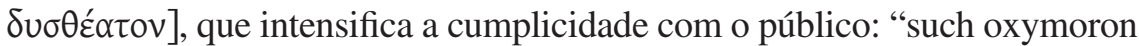
$\left[\theta \varepsilon ́ \alpha \mu \alpha \delta v \sigma \theta \varepsilon \varepsilon_{\alpha \tau} \tau v\right]$ is characteristic of tragic diction. Part of P.'s punishment consists of the humiliation of being stared at by others; yet he is eager to summon witness to his unjust sufferings." (GRIFFITH, 1983, p. 97).

Saïd assevera que no teatro de Ésquilo as aparências revelam, e não encobrem, a realidade. No caso específico do Prometeu, está em jogo um elemento especialmente importante para a sua compreensão: "In Aeschylean drama appearances never deceive. (...) In Prometheus Bound Cratos' harsh speech is matched by his ugly look (cf. 78)." (SAÏD, 2008, p. 228). Dimensiona-se por esse modo uma estratégia decisiva em seu jogo visual por cujo intermédio torna o publico em testemunha. A esse respeito, é esclarecedora uma observação de Hefesto, para quem a dureza da voz e aparência de Poder irmanam-se: "Tua língua repercute em tua figura." (A. Pr. 78). Língua ( $\operatorname{lossa}$ ) e fisionomia (morphe) correspondem-se. Tal estilo, tal caráter.

Prometeu, pouco antes da entrada em cena das Oceânides, ainda sem estar certo da identidade de quem se aproximava, diz que estavam prestes a testemunhar um desafortunado deus em cadeias: "Aprisionado, vês um deus soturno" (119). Esse construto visual se repetirá em diversos momentos, como nesta passagem em que Oceano responde ao prisioneiro: "Eu vejo, Prometeu" (307). Com objetivo similar dirige-se a Io, informando que ela vê, à sua frente, o herói que dera o fogo aos homens: "Sou Prometeu, que aos homens deu o fogo." (612). Faz-se necessário um pequeno reparo na tradução: "Vês Prometeu..." (orais Promethea). Outro trecho que evidencia esses mecanismos retóricos ocorre após Prometeu pedir às Oceânides que o vejam acorrentado ao rochedo, a que elas respondem: 
"Eu vejo, Prometeu" (143). Mas não apenas isso: compadecem-se até às lágrimas de tamanho infortúnio:

\author{
uma neblina amarga \\ de lágrimas me assoma aos olhos \\ ao ver teu corpo ressecando \\ no pétreo topo, \\ em tais ultrajes de aço. (144-8).
}

O vocabulário é acentuadamente visual: olhos (osse), lágrima (dakruon) e o ato de ver (eisidousai). Vemos a cena que elas veem, em mais alguns dos procedimentos retóricos característicos da cena meta-teatral.

A calamidade que adveio a Prometeu, ele o diz, "agride os olhos de quem vê" (238). Sensível ao apelo do titã, o coro afirma (244-7) que preferiria não ter visto (eisidein) tamanho revés, tampouco assitir às (eisidousa) dores que o abatem. A resposta do titã demonstra tanto acolhida à fala do coro, chamando-o de amigo, quanto expressa o quadro visual do temível mal que lhe coube por castigo: "Sim, os amigos sofrem ao me ver" (246). Compreende que seja doloroso (eleinos) aos amigos (philois) observarem (eisoran) a cena. Há ainda um outro elemento importante nessa passagem. Prometeu parece sugerir que a exposição do seu sofrimento não o diminui apenas a ele: é a glória mesma de Zeus que se vê maculada (241). O espetáculo (thea) exibe algo vergonhoso a Zeus (Zeni dysklees). Griffith assim também o compreende: "whereas there [194-5] Zeus was seen as 'humiliating' P., here, after the true story has been heard, it is Zeus' own

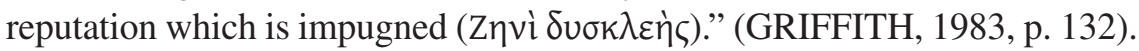
Por tratar-se de cena em segundo grau, o espetáculo do tirano revelado indigno, ridículo em seus atos repletos de prepotência e aleivosia, tem seu impacto dramático ampliado.

Em sua chegada, Oceano é recebido com uma série de perguntas (A. Pr. 298-303). Vem como espectador (epoptes) das desventuras do titã (299)? Surge para observar as dores (e theoreson tychas) do prisioneiro (302) e compartir de alguma sorte de indignação (synaschalon) com o que testemunha (303)? Prometeu assim pede ao visitante: "Contempla o espetáculo" (304). Convém sublinhar que o termo grego para espetáculo, theama, pertence à mesma raiz de theatron. Nas múltiplas implicações desse jogo, uma delas liga-se a pressupostos meta-teatrais que esmaecem a clareza da percepção das bordas da cena. E a resposta de Oceano é também visual, ainda que 
A partilha da dor e do silêncio:

vá intervir por via sobremodo equivocada na peça, movido que era por excessiva prudência: "Eu vejo, Prometeu” (307).

No decurso do seu encontro com Io, Prometeu busca incentivá-la a narrar o seu sofrimento (esp. 638-9), com a ponderação de ser recompensador o lamento que se pode colher em troca das lágrimas de quem nos ouve (tis oisesthai dakry pros ton kluonton). Configura-se aqui um dos momentos mais explícitos de cena duplicada, pois quem os ouve, fundamentalmente, senão o próprio público? Prometeu assegura que ele mesmo será para Io o público que a eles assiste.

Em outra passagem, logo que divisa a chegada de Hermes (941), o titã assevera que vê (eisoro) o mensageiro de Zeus (ton Dios trochin), o servo do novo tirano (942). Será um episódio marcado por diálogo acerbo entre ambos, com altercações sucessivas. A discordância entre ambos encontra perfeito arremate numa luta pela nomeação ${ }^{13}$. Em última instância, entre eles não pode sequer haver o menor indício de diálogo - a tirania abalou mesmo essa possibilidade. Na consumação de toda essa cadeia de lutas e acusações, chegamos ao último verso (1093), a marcar o apelo de Prometeu à mãe para que testemunhe, veja (esorais) o sofrimento injusto (ekdika pascho) do filho - invocação que também se dirige, com sutileza e engenho, a todo o público, agora tornado sua testemunha.

$\mathrm{O}$ estudo desse vocabulário permite assim conceder relevo à tessitura visual da obra. O drama concita os interlocutores de Prometeu e o público a testemunharem os temíveis eventos por meio do concurso de todos esses elementos, assim urdindo os fios da persuasão retórica em favor da filantropia, do sentir-com o protagonista as suas dores e agonias. Forma sobremodo

13 O pólemos da nomeação constitui o cerne do agon em diversas peças trágicas gregas. Conferir, por exemplo, A. Eu.: 179-234 (diálogo entre as Erínias e Apolo), 588-613 (Orestes e as Erínias); S. Ant.: 441-525 (Creonte e Antígona); S. OT: 316-379, 432-462 (Tirésias e Édipo), 532-629 (Édipo e Creonte - esta passagem é um dos pontos altos desse gênero de diálogo); S. Ph.: 975-1044 (Filoctetes e Odisseu), 1222-1258 (Odisseu e Neoptólemo).

Não escapou a Aristóteles um pormenor cênico de grande importância para a montagem do agon: a progressiva incorporação do segundo e terceiro ator entre os tragediógrafos gregos: "O primeiro a mudar o número de actores de um para dois foi Ésquilo (...). Sófocles aumentou o número de actores para três e introduziu a cenografia." (Arist, Po. 1449a 15-19 - trad. Ana Maria Valente). Após Sófocles haver introduzido o terceiro ator, Ésquilo passa também a utilizá-lo, inicialmente de modo frugal, até conduzir seu uso a um plano rico nas Eumênides: "But in Eumenides the trial scene (566-777) makes effective use of three actors (Athena, Apollo, and Orestes).” (SAÏD, 2008, p. 219). 
engenhosa com a qual o escritor compôs não apenas a cena de malogro e desengano, mas também, e sobretudo, da partilha e da escuta cúmplices.

\section{Referências bibliográficas}

AESCHYLUS. Prometheus bound. Ed. Mark Griffith. Cambridge: Cambridge University Press, 1983.

ALCMEONE. Trad. Maria Timpanaro Cardini. In.: DIELS, Hermann e KRANZ, Walther. I Presocratici. $3^{\text {a }}$. ed. Trad. Giovanni Reale et. al. Milano: Bompiani, 2006.

ARISTÓFANES. As rãs. Trad. Américo da Costa Ramalho. Lisboa: Edições 70, 2008.

ARISTÓTELES. Poética. Trad. Ana Maria Valente. 4a. ed. Lisboa: Calouste Gulbenkian, 2011.

BENJAMIN, Walter. Para uma crítica da violência. Trad. Ernani Chaves. In Escritos sobre mito e linguagem. Trad. Susana Kampff e Ernani Chaves. São Paulo: Duas Cidades; Editora 34, 2011.

ÉSQUILO. Prometeu prisioneiro. Trad. Trajano Vieira. In.: ALMEIDA, Guilherme de; VIEIRA, Trajano. Três tragédias gregas: Antígone, Prometeu prisioneiro, Ájax. São Paulo: Perspectiva, 2007.

GRIFFITH, Mark. The authenticity of Prometheus bound. Cambridge: Cambridge University Press, 1977.

Commentary. In AESCHYLUS. Prometheus bound. Ed. Mark Griffith. Cambridge: Cambridge University Press, 1983.

HALL, Edith. Greek tragedy: suffering under de sun. Oxford: Oxford University Press, 2010.

HERINGTON, John. Aeschylus. New Haven: Yale University Press, 1986.

LIDDELL, Henry George; SCOTT, Robert. A Greek-English Lexicon. Oxford: Clarendon Press, 1940. In.: THESAURUS LINGUAE GRAECAE. http:// stephanus.tlg.uci.edu/lsj/\#eid=1\&context=lsj (acessado em 29 de março de 2014).

LORAUX, Nicole. The mourning voice: an essay on Greek tragedy. Trad. Elizabeth Tapnell Rawlings. New York: Cornell University Press, 2002.

A tragédia grega e o humano. Trad. Maria Lúcia Machado. In.: NOVAES, Adauto (org.), Ética. São Paulo: Companhia das Letras, 1992.

PLATÃO. República. Trad. e notas Maria Helena da Rocha Pereira. 6a. ed. Lisboa: Calouste Gulbenkian, 1990. 
A partilha da dor e do silêncio:

estratégias meta-teatrais no Prometeu Agrilhoado de Ésquilo

PODLECKI, Anthony J. The political background of Aeschylean tragedy. 2a . ed. London: Bristol Classical Press, 1999.

REHM, Rush. The play of space: spatial transformation in Greek tragedy. New Jersey: Princeton University Press, 2002.

SAÏD, Suzanne. Aeschylean tragedy. In.: GREGORY, Justina. A companion do Greek tragedy. Oxford: Blackwell Publishing, 2008.

. Sophiste et tyran, ou le problème du Prométhée enchaîné. Paris: Klinckisieck, 1985.

SILVA, Maria de Fátima de Sousa e. Ésquilo: o primeiro dramaturgo europeu. Coimbra: Imprensa da Universidade de Coimbra, 2005

SOMMERSTEIN, Alan H. Aeschylean tragedy. London: Duckworth, 2010.

SOTTOMAYOR, Ana Paula Quintela. Introdução. In.: ÉSQUILO. Prometeu agrilhoado. Trad. Ana Paulo Quintela Sottomayor. Lisboa: Edições 70, 2008.

TAPLIN, Oliver. Aeschylean silences and silences in Aeschylus. Harvard Studies in Classical Philology, vol. 76 (1972), p. 57-97.

VIEIRA, Trajano. Tirania olímpica. In.: ALMEIDA, Guilherme de; VIEIRA, Trajano. Três tragédias gregas: Antígone, Prometeu prisioneiro, Ájax. São Paulo: Perspectiva, 2007.

WINNINGTON-INGRAM, R. P. Aeschylus. In.: EASTERLING, P. E.; KNOX, B. M. W. The Cambridge history of classical literature I: Greek literature. Cambridge: Cambridge University Press, 2008. 